\title{
Telomere length, pre-eclampsia, and gestational diabetes
}

\author{
Emily W Harville*1, Michelle A Williams 2,3 , Chun-fang Qiu², Julie Mejia ${ }^{4}$ and Rosa Ana Risques ${ }^{4}$
}

\begin{abstract}
Background: Telomere length is a marker of cumulative damage to the cell, and has been associated with cardiovascular disease, hypertension, and diabetes.

Findings: The association of telomere length with pre-eclampsia and gestational diabetes mellitus (GDM) was examined in a nested case-control study. Circulating leukocyte telomere length was measured by Quantitative-PCR. Mean and median telomere length among cases and controls was compared, and logistic regression was used to model the outcomes as a function of tertile telomere length, with control for effects of potential confounders. Mean telomere length in pre-eclampsia cases was 0.77 (SD 0.14), in GDM cases was 0.73 (SD 0.10), and in controls was 0.74 (SD 0.14). The adjusted odds ratio comparing the highest tertile to the lowest for pre-eclampsia was 0.92 (0.15-5.46), and for gestational diabetes was 0.65 (0.13-3.34).
\end{abstract}

Conclusions: Further study is necessary to determine if telomere length is associated with these pregnancy complications.

\section{Background}

Telomeres are terminal regions of chromosomes that comprise multiple tandem repeats of a base sequence[1] Telomere length is a marker of the cumulative damage the cell has been exposed to [2], and has been associated with cardiovascular disease[3], general cardiovascular damage [4], and atherosclerosis [5]. Hypertensive patients have been reported to have shorter telomeres [69], especially when they had high renin to aldosterone ratios[10]. Similarly, blood pressure has been associated with shorter telomeres and low telomerase activity [1113] Diabetes patients have been shown to have shorter telomeres in several studies, [11,14-17] and increased telomere attrition [18] and shorter telomere length $[6,19]$ have been associated with insulin resistance. Higher glucose and insulin were associated with shorter telomeres $[11,20]$ and low telomerase activity [12], while good glycemic control was associated with more favorable telomere dynamics $[17,20]$

Telomere length and dynamics vary substantially between individuals [21] and are influenced by a number

* Correspondence: eharvill@tulane.edu

1 Department of Epidemiology, Tulane School of Public Health and Tropical Medicine, New Orleans, LA, USA

Full list of author information is available at the end of the article of factors, including genetics and family relationship $[13,22,23]$, multivitamin use [23], race [21], smoking $[12,21,24]$, and body mass index $[6,18,24]$.

Pre-eclampsia is associated with increased risk of cardiovascular disease [25] and gestational diabetes is associated with increased risk of later diabetes[26], suggesting that risk factors and etiologies of cardiovascular disease and diabetes and these outcomes is likely to be similar. Thus, a reasonable hypothesis is that telomere length will also differ in patients with these outcomes. In addition, telomere length has been associated with oxidative stress, $[16,27]$ and markers of oxidative stress are raised in preeclampsia[28] A recent article found lower telomere length in the placentas of women with pre-eclampsia and intrauterine growth retardation[29] We are unaware of other previous studies of telomere length in pre-eclampsia and gestational diabetes. For studies related to reproductive outcomes, no difference in telomere lengths was found in young adults whose mothers had pre-gestational type 1 diabetes[30], while another study of newborns did not find statistically significant differences in telomere lengths between newborns whose mothers had preeclampsia, hypertension, or diabetes[31]. However, these studies dealt with the child rather than the mothers. 
Table 1: Distribution of Preeclampsia (PE) Cases and Normotensive Control Subjects According to Selected Characteristics, Seattle and Tacoma, Washington, 1998 - 2002.

\begin{tabular}{|c|c|c|c|c|c|}
\hline & \multicolumn{2}{|c|}{ PE Cases } & \multicolumn{2}{|c|}{ Control Subjects } & \multirow[t]{2}{*}{$\mathbf{p}$} \\
\hline & \multicolumn{2}{|c|}{$(N=50)$} & \multicolumn{2}{|c|}{$(\mathrm{N}=50)$} & \\
\hline & $\mathbf{n}$ & $\%$ & $\mathbf{n}$ & $\%$ & \\
\hline Maternal Age (years) & & & & & $<0.01$ \\
\hline $20-24$ & 19 & 38 & 5 & 10 & \\
\hline $25-29$ & 13 & 26 & 14 & 28 & \\
\hline $30-34$ & 18 & 36 & 31 & 62 & \\
\hline Maternal Age (years) ${ }^{\dagger}$ & \multicolumn{2}{|c|}{$27.3 \pm 0.6$} & \multicolumn{2}{|c|}{$29.5 \pm 0.5$} & $<0.01$ \\
\hline \multicolumn{6}{|l|}{ Maternal Race/Ethnicity } \\
\hline Non-Hispanic White & 50 & 100 & 50 & 100 & .. \\
\hline Unmarried & 13 & 26 & 8 & 16 & 0.22 \\
\hline$\leq 12$ years Education & 15 & 30 & 3 & 6 & $<0.01$ \\
\hline Nulliparous & 50 & 100 & 50 & 100 & $\ldots$ \\
\hline Smoked During Pregnancy & 11 & 22 & 7 & 14.8 & 0.06 \\
\hline Pre-pregnancy BMI*† & \multicolumn{2}{|c|}{$26.9 \pm 0.9$} & \multicolumn{2}{|c|}{$22.4 \pm 0.4$} & $<0.01$ \\
\hline Pre-pregnancy BMI* & & & & & $<0.01$ \\
\hline$<20$ & 1 & 2 & 13 & 26 & \\
\hline $20-24.9$ & 25 & 50 & 27 & 54 & \\
\hline $25-29.9$ & 11 & 22 & 8 & 16 & \\
\hline$\geq 30$ & 13 & 26 & 2 & 4 & \\
\hline Annual Household Income (US\$) & & & & & 0.36 \\
\hline$<30,000$ & 9 & 18 & 9 & 18 & \\
\hline $30,000-69,999$ & 24 & 48 & 17 & 34 & \\
\hline $70,000+$ & 17 & 34 & 23 & 46 & \\
\hline Unknown & 0 & 0 & 1 & 2 & \\
\hline Physical inactive during pregnancy & 24 & 48 & 16 & 32 & 0.10 \\
\hline Family history of chronic hypertension & 29 & 58 & 17 & 34 & 0.02 \\
\hline Gestational age at delivery (weeks) & \multicolumn{2}{|c|}{$34.4 \pm 0.6$} & \multicolumn{2}{|c|}{$39.7 \pm 0.2$} & $<0.01$ \\
\hline Time from last meal to blood drawn (hours) & \multicolumn{2}{|c|}{$3.03 \pm 0.53$} & \multicolumn{2}{|c|}{$1.68 \pm 0.19$} & 0.02 \\
\hline Telomere length $^{\dagger}$ & \multicolumn{2}{|c|}{$0.77 \pm 0.02$} & \multicolumn{2}{|c|}{$0.77 \pm 0.02$} & 0.75 \\
\hline Median (inter-quartile range) & \multicolumn{2}{|c|}{$0.75(0.66,0.83)$} & \multicolumn{2}{|c|}{$0.77(0.70,0.84)$} & 0.56 \\
\hline
\end{tabular}

*Pre-pregnancy body mass index $=\mathrm{BMI}=$ weight $(\mathrm{kg}) /$ height $\left(\mathrm{m}^{2}\right)$.

${ }^{+}$Mean \pm SEM;

Recurrent miscarriage has also been associated with shorter telomere length [32], but no difference in telomere length by small-for-gestational-age was seen[22] We examined the relationship between pre-eclampsia, gestational diabetes, and telomere length in a nested case-control study.

\section{Methods}

50 cases of pre-eclampsia, 25 cases of GDM, and 50 controls were selected from an existing study, conducted from April 1998 to June 2002 in Washington State. This study has been described in detail elsewhere [33]. Using the then-current guidelines, preeclampsia was defined as sustained pregnancy-induced hypertension with proteinuria. Hypertension was defined as sustained blood pressure readings of $\geq 140 / 90 \mathrm{mmHg}$ (with readings taking place $\geq 6$ hours apart) and/or a sustained $15 \mathrm{~mm} \mathrm{Hg} \mathrm{dia-}$ stolic rise or a $30 \mathrm{~mm} \mathrm{Hg}$ systolic blood pressure above first-trimester values. Proteinuria was defined as urine protein concentrations of $\geq 30 \mathrm{mg} / \mathrm{dl}$ on $\geq 2$ random specimens collected at least 4 hours apart. In our study setting, according to the recommendations from the 
Table 2: Distribution of Gestational Diabetes Mellitus (GDM) Cases and Normotensive/Euglycemic Control Subjects According to Selected Characteristics, Seattle and Tacoma, Washington, 1998 - 2002.

\begin{tabular}{|c|c|c|c|c|c|}
\hline & \multicolumn{2}{|c|}{ GDM Cases } & \multicolumn{2}{|c|}{ Control Subjects } & \multirow[t]{3}{*}{$\mathbf{p}$} \\
\hline & \multicolumn{2}{|c|}{$(\mathrm{N}=\mathbf{2 5})$} & \multicolumn{2}{|c|}{$(N=50)$} & \\
\hline & $\mathbf{n}$ & $\%$ & $\mathbf{n}$ & $\%$ & \\
\hline Maternal Age (years) & & & & & 0.29 \\
\hline $20-24$ & 3 & 12 & 5 & 10 & \\
\hline $25-29$ & 3 & 12 & 14 & 28 & \\
\hline $30-34$ & 19 & 76 & 31 & 62 & \\
\hline Maternal Age (years) ${ }^{\dagger}$ & \multicolumn{2}{|c|}{$30.9 \pm 0.7$} & \multicolumn{2}{|c|}{$29.5 \pm 0.5$} & 0.08 \\
\hline \multicolumn{6}{|l|}{ Maternal Race/Ethnicity } \\
\hline Non-Hispanic White & 25 & 100 & 50 & 100 & --- \\
\hline Unmarried & 3 & 12 & 8 & 16 & 0.74 \\
\hline$\leq 12$ years Education & 1 & 4 & 3 & 6 & 0.59 \\
\hline Nulliparous & 12 & 48 & 50 & 100 & $<0.01$ \\
\hline Smoked During Pregnancy & 2 & 8 & 7 & 14.8 & 0.54 \\
\hline Pre-pregnancy BMI*† & \multicolumn{2}{|c|}{$27.8 \pm 1.5$} & \multicolumn{2}{|c|}{$22.4 \pm 0.4$} & $<0.01$ \\
\hline Pre-pregnancy BMI* & & & & & $<0.01$ \\
\hline$<20$ & 3 & 12 & 13 & 26 & \\
\hline $20-24.9$ & 7 & 28 & 27 & 54 & \\
\hline $25-29.9$ & 7 & 28 & 8 & 16 & \\
\hline$\geq 30$ & 8 & 32 & 2 & 4 & \\
\hline \multicolumn{6}{|l|}{ Annual Household Income (US\$) } \\
\hline$<30,000$ & 5 & 20 & 9 & 18 & 0.93 \\
\hline $30,000-69,999$ & 7 & 28 & 17 & 34 & \\
\hline $70,000+$ & 12 & 48 & 23 & 46 & \\
\hline Unknown & 1 & 4 & 1 & 2 & \\
\hline $\begin{array}{l}\text { Physical inactive during } \\
\text { pregnancy }\end{array}$ & 10 & 40 & 16 & 32 & 0.49 \\
\hline Family history of diabetes mellitus & 4 & 16 & 3 & 6 & 0.21 \\
\hline Gestational age at delivery (weeks) & \multicolumn{2}{|c|}{$39.0 \pm 0.2$} & \multicolumn{2}{|c|}{$39.7 \pm 0.2$} & 0.05 \\
\hline $\begin{array}{l}\text { Time from last meal to blood } \\
\text { drawn (hours) }\end{array}$ & \multicolumn{2}{|c|}{$3.25 \pm 0.74$} & \multicolumn{2}{|c|}{$1.68 \pm 0.19$} & $<0.01$ \\
\hline Telomere length $^{\dagger}$ & \multicolumn{2}{|c|}{$0.73 \pm 0.02$} & \multicolumn{2}{|c|}{$0.77 \pm 0.02$} & 0.20 \\
\hline Median (inter-quartile range) & \multicolumn{2}{|c|}{$0.72(0.69,0.76)$} & \multicolumn{2}{|c|}{$0.77(0.70,0.84)$} & 0.10 \\
\hline
\end{tabular}

*Pre-pregnancy body mass index $=\mathrm{BMI}=$ weight $(\mathrm{kg}) / \mathrm{height}\left(\mathrm{m}^{2}\right)$. ${ }^{+}$Mean \pm SEM;

American Diabetes Association (ADA) [34] pregnant women were screened at 24-28 weeks gestation using a 50 gram 1-hour oral glucose challenge test. Those patients who failed this screening test (glucose $\geq 7.8 \mathrm{mmol} / \mathrm{L}$ ) were then followed-up within 1-2 weeks with a $100 \mathrm{~g}, 3-\mathrm{h}$ oral glucose tolerance test (OGTT). We also abstracted laboratory results from participants' 50 gram 1-hour glucose challenge test and from the diagnostic 100 gram 3hour OGTT. Women were diagnosed with GDM if two or more of the 100 gram OGTT glucose levels exceeded the ADA criteria [34]: fasting $>5.3 \mathrm{mmol} / \mathrm{L}$; 1 -hour $>10.0$ $\mathrm{mmol} / \mathrm{L}$; 2-hour $>8.6 \mathrm{mmol} / \mathrm{L} ; 3$-hour $>7.8 \mathrm{mmol} / \mathrm{L}$.

Controls were women who delivered within two hours of a case with pregnancies uncomplicated by pregnancyinduced hypertension. A structured interview questionnaire, administered during participants' postpartum hospital stay, was used to collect information on maternal sociodemographic, medical, reproductive, and lifestyle 
characteristics during in-person interviews. The women chosen for this analysis were required to be between 2035 years old, non-Hispanic white, with no pre-existing hypertension or diabetes, and carrying a singleton pregnancy.

Non-fasting blood samples were collected in $10 \mathrm{ml}$ tripotassium EDTA Vacutainer tubes during the intrapartum period. These were protected from ultraviolet light, kept on wet ice, and processed within 30 minutes of phlebotomy. Plasma was decanted into cryovials and kept frozen at $-70^{\circ} \mathrm{C}$ or below until analysis.

Leucocyte telomere length (hereafter referred to as telomere length) was measured by Quantitative-PCR using the method described by Cawthon [35]. Briefly, for each sample, two PCRs are performed: the first one to amplify the telomeric DNA and the second one to amplify a single-copy control gene (36B4, acidic ribosomal phosphoprotein $\mathrm{PO}$ ). This provides an internal control to normalize the starting amount of DNA. The amount of telomeric DNA is divided by the amount of control-gene DNA, producing a relative measurement of the telomere length of the sample. The average interexperimental coefficient of variation was 0.05 .

Sample size for this study was determined based on other studies of telomere length. Comparing groups of 50 gives us better than $90 \%$ power to see a difference as large as that seen in a paper demonstrating reduced telomere length under chronically stressful conditions [36]. Fifty per group gives us $80 \%$ power to see an odds ratio of 3.2 for top vs. bottom quartile, lower than the hazard ratio of 3.5 seen in previous studies of telomere length and cancer [37]. Several studies of this size looking at telomere length and reproductive outcomes have been published[22,30,32]

Mean and median telomere length among cases and controls was compared using t-tests and Wilcoxon nonparametric tests. Telomere length was divided into tertile based on the control group, and logistic regression was used to model the outcomes as a function of tertile telomere length, with control for effects of potential confounders. In addition, the association between telomere length and other variables was examined within cases and controls.

Ethics approval for the initial study was granted by the University of Washington Institutional Review Board, and informed consent (including for sample banking) was gathered from all subjects. Tulane University IRB granted approval for this secondary analysis.

\section{Results}

Pre-eclampsia cases were on average younger, heavier, more likely to smoke, less likely to have higher education, and more likely to have a family history of hypertension than controls (table 1). GDM cases were on average older, heavier, and more likely to have a family history of diabetes (table 2). Mean telomere length in pre-eclampsia cases

Table 3: Odds Ratios (OR) and 95\% Confidence Intervals (CI) for Preeclampsia (PE) and gestational diabetes mellitus (GDM) according to Tertiles of Maternal Blood DNA Telomere Length Sampled at Delivery, Seattle, Washington, 1998-2002.

\begin{tabular}{|c|c|c|c|c|c|}
\hline Telomere length & Preeclampsia $(\mathrm{N}=50)$ & $\begin{array}{l}\text { Controls } \\
(\mathrm{N}=50)\end{array}$ & $\begin{array}{c}\text { Unadjusted OR } \\
(95 \% \mathrm{Cl})\end{array}$ & $\begin{array}{c}\text { Age-adjusted OR } \\
(95 \% \mathrm{Cl})\end{array}$ & $\begin{array}{c}\text { Adjusted OR* } \\
(95 \% \mathrm{Cl})\end{array}$ \\
\hline Tertile $1(<0.720)$ & 23 & 19 & 1.00 (reference) & 1.00 (reference) & 1.00 (reference) \\
\hline Tertile $2(0.720-0.800)$ & 8 & 15 & $0.44(0.15-1.26)$ & $0.45(0.15-1.35)$ & $0.46(0.62-3.38)$ \\
\hline Tertile 3 ( $\geq 0.801)$ & 19 & 16 & $0.98(0.40-2.41)$ & $1.08(0.42-2.75)$ & $0.92(0.15-5.46)$ \\
\hline$P$ for trend & & & 0.91 & 0.94 & 0.83 \\
\hline Telomere length & $\begin{array}{c}\text { GDM } \\
(\mathrm{N}=\mathbf{2 5})\end{array}$ & $\begin{array}{l}\text { Controls } \\
(\mathrm{N}=50)\end{array}$ & $\begin{array}{l}\text { Unadjusted OR } \\
\qquad(95 \% \mathrm{Cl})\end{array}$ & $\begin{array}{c}\text { Age-Adjusted OR } \\
(95 \% \mathrm{Cl})\end{array}$ & $\begin{array}{c}\text { Adjusted OR* } \\
(95 \% \mathrm{Cl})\end{array}$ \\
\hline Tertile $1(<0.720)$ & 14 & 19 & 1.00 (reference) & 1.00 (reference) & 1.00 (reference) \\
\hline Tertile $2(0.720-0.800)$ & 6 & 15 & $0.54(0.17-1.75)$ & $0.56(0.17-1.87)$ & $0.96(0.19-4.77)$ \\
\hline Tertile 3 ( $\geq 0.801)$ & 5 & 16 & $0.42(0.13-1.43)$ & $0.35(0.10-1.23)$ & $0.65(0.13-3.34)$ \\
\hline$P$ for trend & & & 0.15 & 0.09 & 0.61 \\
\hline
\end{tabular}

The cutoffs of tertile were based on the distribution in controls

* adjusted for maternal age, pre-pregnancy body mass index, gestational age at delivery and time from last meal to blood draw. 
was 0.77 (SD 0.14), in GDM cases was 0.73 (SD 0.10), and in controls was 0.77 (SD 0.14). If the pre-eclampsia cases were limited to those who gave birth preterm $(n=30)$, mean telomere length was 0.79 (SD 0.15), which was not significantly different from that of controls. Odds of preeclampsia were lowest in the middle tertile of telomere length and essentially equal in the lowest and highest tertiles in the unadjusted and both adjusted models (table 3). There was evidence of reduced risk of GDM with the highest tertile of telomere length, though the associations did not reach statistical significance in any of the 3 models tested.

Among controls, covariates were examined for relationships with telomere length. There was some evidence of association with telomere length for hours since last meal $(\mathrm{r}=0.24, \mathrm{p}=0.09)$ and birthweight $(\mathrm{r}=0.24, \mathrm{p}=$ 0.10 ). Among the controls, mean telomere length was shorter in preterm infants $(0.69$ vs. $0.78, \mathrm{p}=0.26)$, ever smokers $(0.74$ and $0.79, p=0.25)$, unmarried women $(0.72$ vs. $0.78, \mathrm{p}=0.18)$, and those who had eaten most recently $(0.73$ vs. $0.82, \mathrm{p}=0.05)$.

\section{Discussion}

The main findings of the study are (1) no association of telomere length with pre-eclampsia, and (2) shorter telomeres associated with gestational diabetes, but differences might be due to chance. The findings for preeclampsia are in contrast with previous studies that have reported shorter telomeres in individuals with hypertension and blood pressure [6-9,11-13], as well as a study finding shorter telomeres in the placentas of pre-eclamptic women[29] It may be that telomere attrition in hypertension may take years to accumulate, at least in leucocytes, and thus is not apparent in acute pre-eclamptic hypertension. However, some prior studies that explored the association of telomere length with cardiovascular diseases also failed to find an association with hypertension, [11,38] suggesting that this association may depend on the characteristics of the study population.

We found a trend of shorter telomeres in women with gestational diabetes. This is in agreement with previous studies that have reported shorter telomeres in individuals with type 2 diabetes mellitus[11,14,16,19] The lack of statistical significance in our study is likely to be due to the small number of cases, as leukocyte telomere length is highly variable between individuals, or the trend we see could simply be due to chance variation. In addition, as with pre-eclampsia, variations in the pregnancy-related and chronic form of this disease and the characteristics of the study population could also account for the lack of significant association in this study.

The difference in mean telomere length for preeclampsia was 0.008 , with a standard deviation of approximately 0.14 . To have $80 \%$ power to see a difference that large, more than 5000 samples would need to be tested. To see an odds ratio of 0.92 , approximately 8000 samples would be required. The difference in mean telomere length for GDM was 0.01 , with a standard deviation of approximately 0.14 . To have $80 \%$ power to see a difference that large, more than 3000 samples would need to be tested. To have $80 \%$ power to see an odds ratio of 0.65 , approximately 325 cases and controls would be required. Thus, in both cases a much larger set of samples than that included in this study would be needed. Moreover, future studies should also address the analysis of additional markers of oxidative stress as well as leukocyte telomerase activity, as these parameters might help elucidate the biological and functional role of telomere shortening in these diseases.

\section{Conclusions}

The odds ratio for GDM was lowest in the highest tertile of telomere length, but the associations did not reach statistical significance. No association was seen with preeclampsia. Further research is necessary to determine if telomere length is associated with pregnancy complications or outcomes.

\section{Abbreviations}

GDM: gestational diabetes mellitus; ADA: American Diabetes Association; OGTT: oral glucose tolerance test.

\section{Competing interests}

The authors declare that they have no competing interests.

\section{Authors' contributions}

EH conceptualized the study and took the lead in writing the paper. MW supervised the pre-eclampsia and diabetes studies and assisted in writing the paper. CQ assisted in organizing the study and data analysis. JM and RR performed laboratory analyses and assisted in writing the paper. All authors read and approved the final manuscript.

\section{Acknowledgements}

Grant support: Nathan Shock Center, P30 AG13280.

Tulane Research Enhancement Awards.

Dr. Harville was supported by Award Number K12HD043451 from the Eunice Kennedy Shriver National Institute of Child Health \& Human Development. The content is solely the responsibility of the authors and does not necessarily represent the official views of the Eunice Kennedy Shriver National Institute of Child Health \& Human Development or the National Institutes of Health.

\section{Author Details}

1 Department of Epidemiology, Tulane School of Public Health and Tropical Medicine, New Orleans, LA, USA, ${ }^{2}$ Center for Perinatal Studies, Swedish Medical Center, Seattle, WA, USA, ${ }^{3}$ Department of Epidemiology, University of Washington School of Public Health and Community Medicine, Seattle, WA USA and ${ }^{4}$ Department of Pathology, University of Washington, Seattle, WA, USA

Received: 4 November 2009 Accepted: 23 April 2010 Published: 23 April 2010

\section{References}

1. von Zglinicki T, Martin-Ruiz CM: Telomeres as biomarkers for ageing and age-related diseases. Curr Mol Med 2005, 5(2):197-203.

2. Adams JM, White M: Biological ageing: a fundamental, biological link between socio-economic status and health? Eur J Public Health 2004 14(3):331-334. 
3. Cawthon R, Smith KR, O'Brien E, Sivatchenko A, Kerber RA: Association between telomere length in blood and mortality in people aged 60 years or older. Lancet 2003, 361:393-395.

4. Nakashima H, Ozono R, Suyama C, Sueda T, Kambe M, Oshima T: Telomere attrition in white blood cell correlating with cardiovascular damage. Hypertens Res 2004, 27(5):319-325.

5. Samani NJ, Boultby R, Butler R, Thompson JR, Goodall AH: Telomere shortening in atherosclerosis. Lancet 2001, 358(9280):472-473.

6. Demissie S, Levy D, Benjamin EJ, Cupples LA, Gardner JP, Herbert A, Kimura M, Larson MG, Meigs JB, Keaney JF, Aviv A: Insulin resistance, oxidative stress, hypertension, and leukocyte telomere length in men from the Framingham Heart Study. Aging Cell 2006, 5(4):325-330.

7. Yang Z, Huang $X$, Jiang $H$, Zhang $Y$, Liu H, Qin C, Eisner GM, Jose PA, Rudolph L, Ju Z: Short telomeres and prognosis of hypertension in a chinese population. Hypertension 2009, 53(4):639-645.

8. Lung FW, Ku CS, Kao WT: Telomere length may be associated with hypertension. J Hum Hypertens 2008, 22(3):230-232.

9. Fuster JJ, Diez J, Andres V: Telomere dysfunction in hypertension. $J$ Hypertens 2007, 25(11):2185-2192.

10. Vasan RS, Demissie S, Kimura M, Cupples LA, Rifai N, White C, Wang TJ, Gardner JP, Cao X, Benjamin EJ, Levy D, Aviv A: Association of leukocyte telomere length with circulating biomarkers of the renin-angiotensinaldosterone system: the Framingham Heart Study. Circulation 2008, 117(9):1138-1144.

11. Fitzpatrick AL, Kronmal RA, Gardner JP, Psaty BM, Jenny NS, Tracy RP, Walston J, Kimura M, Aviv A: Leukocyte telomere length and cardiovascular disease in the cardiovascular health study. Am J Epidemiol 2007, 165(1):14-21.

12. Epel ES, Lin J, Wilhelm FH, Wolkowitz OM, Cawthon R, Adler NE, Dolbier C, Mendes WB, Blackburn EH: Cell aging in relation to stress arousal and cardiovascular disease risk factors. Psychoneuroendocrinology 2006, 31(3):277-287.

13. Jeanclos E, Schork NJ, Kyvik KO, Kimura M, Skurnick JH, Aviv A: Telomere length inversely correlates with pulse pressure and is highly familial. Hypertension 2000, 36(2):195-200.

14. Uziel O, Singer J, Danicek V, Sahar G, Berkov E, Luchansky M, Fraser A, Ram $R$, Lahav M: Telomere dynamics in arteries and mononuclear cells of diabetic patients: effect of diabetes and of glycemic control. Exp Gerontol 2007, 42(10):971-978

15. Jeanclos E, Krolewski A, Skurnick J, Kimura M, Aviv H, Warram JH, Aviv A: Shortened telomere length in white blood cells of patients with IDDM. Diabetes 1998, 47(3):482-486.

16. Sampson MJ, Winterbone MS, Hughes JC, Dozio N, Hughes DA: Monocyte telomere shortening and oxidative DNA damage in type 2 diabetes. Diabetes Care 2006, 29(2):283-289.

17. Uziel O, Singer JA, Danicek V, Sahar G, Berkov E, Luchansky M, Fraser A, Ram R, Lahav M: Telomere dynamics in arteries and mononuclear cells of diabetic patients: effect of diabetes and of glycemic control. Exp Gerontol 2007, 42(10):971-978

18. Gardner JP, Li S, Srinivasan SR, Chen W, Kimura M, Lu X, Berenson GS, Aviv $A$ : Rise in insulin resistance is associated with escalated telomere attrition. Circulation 2005, 111(17):2171-2177.

19. Adaikalakoteswari A, Balasubramanyam M, Mohan V: Telomere shortening occurs in Asian Indian Type 2 diabetic patients. Diabet Med 2005, 22(9):1151-1156

20. Olivieri F, Lorenzi M, Antonicelli R, Testa R, Sirolla C, Cardelli M, Mariotti S, Marchegiani F, Marra M, Spazzafumo L, Bonfigli AR, Procopio A: Leukocyte telomere shortening in elderly Type2DM patients with previous myocardial infarction. Atherosclerosis 2009, 206(2):588-93.

21. Aviv A, Chen W, Gardner JP, Kimura M, Brimacombe M, Cao X, Srinivasan SR, Berenson GS: Leukocyte telomere dynamics: longitudinal findings among young adults in the Bogalusa Heart Study. Am J Epidemiol 2009, 169(3):323-329.

22. Akkad A, Hastings R, Konje JC, Bell SC, Thurston H, Williams B: Telomere length in small-for-gestational-age babies. Bjog 2006, 113(3):318-323.

23. Xu Q, Parks CG, DeRoo LA, Cawthon RM, Sandler DP, Chen H: Multivitamin use and telomere length in women. Am J Clin Nutr 2009 , 89(6):1857-1863.

24. Parks CG, Miller DB, McCanlies EC, Cawthon RM, Andrew ME, DeRoo LA, Sandler DP: Telomere length, current perceived stress, and urinary stress hormones in women. Cancer Epidemiol Biomarkers Prev 2009 18(2):551-560
25. Sattar N, Greer IA: Pregnancy complications and maternal cardiovascular risk: opportunities for intervention and screening? BMJ 2002, 325:157-160.

26. Metzger B: Long-term outcomes in mothers diagnosed with gestational diabetes mellitus and their offspring. Clin Obstet Gynecol 2007, 50(4):972-979.

27. Saretzki G, Von Zglinicki T: Replicative aging, telomeres, and oxidative stress. Ann N Y Acad Sci 2002, 959:24-29.

28. Orhan H, Onderoglu L, Yucel A, Sahin G: Circulating biomarkers of oxidative stress in complicated pregnancies. Arch Gynecol Obstet 2003 267(4):189-195

29. Biron-Shental T, Sukenik-Halevy R, Sharon Y, Goldberg-Bittman L, Kidron $D$, Fejgin MD, Amiel A: Short telomeres may play a role in placental dysfunction in preeclampsia and intrauterine growth restriction. Am J Obstet Gynecol 202(4):e381-387.

30. Cross JA, Brennan C, Gray T, Temple RC, Dozio N, Hughes JC, Levell NJ, Murphy H, Fowler D, Hughes DA, Sampson MJ: Absence of telomere shortening and oxidative DNA damage in the young adult offspring of women with pre-gestational type 1 diabetes. Diabetologia 2009, 52(2):226-234

31. Okuda K, Bardeguez A, Gardner JP, Rodriguez P, Ganesh V, Kimura M, Skurnick J, Awad G, Aviv A: Telomere length in the newborn. Pediatr Res 2002, 52(3):377-381

32. Hanna CW, Bretherick KL, Gair JL, Fluker MR, Stephenson MD, Robinson WP: Telomere length and reproductive aging. Hum Reprod 2009, 24(5):1206-1211.

33. Sorensen TK, Williams MA, Lee IM, Dashow EE, Thompson ML, Luthy DA: Recreational physical activity during pregnancy and risk of preeclampsia. Hypertension 2003, 41:1273-1280.

34. Gestational diabetes mellitus. Diabetes Care 2004, 27(Suppl 1):88-90

35. Cawthon R: Telomere measurement by quantitative PCR. Nucleic Acids Res 2002, 30(10):e47.

36. Epel ES, Blackburn EH, Lin J, Dhabhar FS, Adler NE, Morrow JD, Cawthon RM: Accelerated telomere shortening in response to life stress. PNAS 2004, 101(49):17312-17315.

37. Risques RA, Vaughan TL, Li X, Odze RD, Blount PL, Ayub K, Gallaher JL, Reid $B J$, Rabinovitch PS: Leukocyte telomere length predicts cancer risk in Barrett's esophagus. Cancer Epidemiol Biomarkers Prev 2007, 16(12):2649-2655.

38. Brouilette S, Singh RK, Thompson JR, Goodall AH, Samani NJ: White cell telomere length and risk of premature myocardial infarction. Arterioscler Thromb Vasc Biol 2003, 23(5):842-846.

doi: 10.1186/1756-0500-3-113

Cite this article as: Harville et al., Telomere length, pre-eclampsia, and gestational diabetes BMC Research Notes 2010, 3:113

\section{Submit your next manuscript to BioMed Central and take full advantage of:}

- Convenient online submission

- Thorough peer review

- No space constraints or color figure charges

- Immediate publication on acceptance

- Inclusion in PubMed, CAS, Scopus and Google Scholar

- Research which is freely available for redistribution 